\title{
Design and Application of Strain Brushless Torque Sensor
}

\author{
Jiaming Zhang ${ }^{*}$, Gong Chen, Wenrui Wang and Hao Sun \\ School of Mechanical Engineering, University of Science and Technology Beijing, Beijing, China \\ ${ }^{*}$ Corresponding author
}

\begin{abstract}
The torque monitoring of high-speed rotary shaft is often unsuccessful because of sensor installation, reliability, accuracy and other practical issues, so high-speed rotary shaft torque monitoring has become an urgent need. The brushless torque sensor is developed based on strain measurement, which transformed the torque to the deformation of the shell, the torque value is obtained by strain measurement of the shell, the measurement error is less than $4 \%$ by experimental verification. In a torque measurement of cold rolling mill main transmission shaft, the torque vibration data is verified by inherent characteristic simulation of rolling mill drive system, and the torque amplitude data is verified by motor power and speed signals. It is proved that the strain brushless torque sensor is feasible and the measurement result is correct, which provides a basis for other high-speed rotating shaft torque detection works.
\end{abstract}

Keywords-torque sensor; strain gauge; rolling mill vibration; torque vibration; inherent characteristic

\section{INTRODUCTION}

The rotating shaft of large generator set, rolling mill and wind power generator and other heavy industry complex equipment is often damaged by fatigue crack which is caused by torque overload. Torque online monitoring is also important basis of power system condition judgment and fault diagnosis[1-3].

Common contact torque sensor and ring-type torque sensor transit signal by slip ring or wireless emitter. They have the disadvantages of limited measuring time and rotate rate due to the abrasion wear and battery life[4-6]. Rotary torque measurement has always been a difficulty for testing researchers, which needs good performance in torque sensor structure design, measuring method, reliability, long term stability and environmental adaptability [7-9].

This article develops a brushless torque sensor with independent intellectual property rights based on strain electric technology, which realizes the accurate measurement of rotary shaft torque. The brushless torque sensor transmits the torque of shaft into tensile deformation of the shell, and the torque value is deduced from measurement result of the shell [10-12].

\section{Structure Of Brushless Torque SENSOR}

\section{A. Working Principle of the Torque Sensor}

The brushless torque sensor in this article mainly consists of four parts, transmission shaft, steel belt, tumbler and shell, as shown in figure 1.

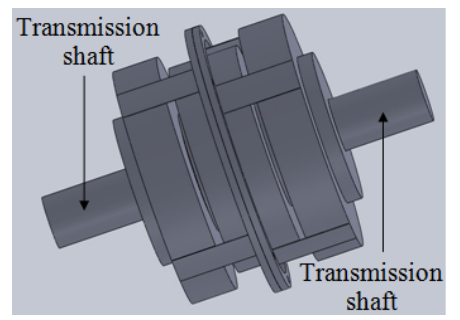

(a)Entire assembly drawing

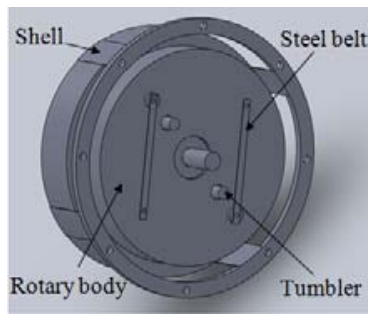

(b) Half assembly drawing
FIGURE I. ASSEMBLY DRAWING OF BRUSHLESS TORQUE SENSOR

The brushless torque sensor in this article mainly consists of four parts, transmission shaft, steel belt, tumbler and shell, as shown in figure 1.

The brushless torque sensor is installed between tested shafts and rotates with the shafts. Steel belt connects two rotating bodies, and transmits the torque from driving shaft to driven shaft. The deformation of steel belt produces a corner between two rotary bodies, the tumbler's height increases when there is a corner, and transmits the corner into axial displacement. Strain gauges are mounted on the shell to measure the strain and calculate the torque value.

\section{B. Key Parameter Design of the Tumbler}

As shown in figure 3 , the height increase of tumbler is $\Delta H=B B^{\prime}-\mathrm{H} . B B^{\prime}$ is got according to tumbler height and height increase $\Delta H$, and $\mathrm{OO}_{2}=\mathrm{R}-\mathrm{H} / 2$ is calculated on the basis of spherical radius $\mathrm{R}$.

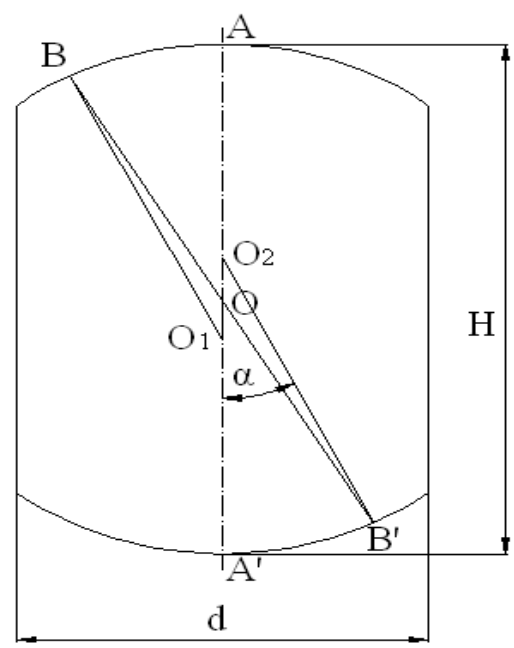

FIGURE II. WORKING PRINCIPLE DIAGRAM OF THE TUMBLER 
In $\Delta \mathrm{OO}_{2} \mathrm{~B}^{\prime}$, we can get the equation below according to law of cosines.

$$
\cos \alpha=\frac{R^{2}+\left(\mathrm{OO}_{2}\right)^{2}-\left(O B^{\prime}\right)^{2}}{2 \times \mathrm{OO}_{2} \times R}
$$

By the computation above, we can get the corner $\alpha$ of the tumbler when the height increase is $\Delta H$.

\section{Key Parameter Design of the Steel Belt}

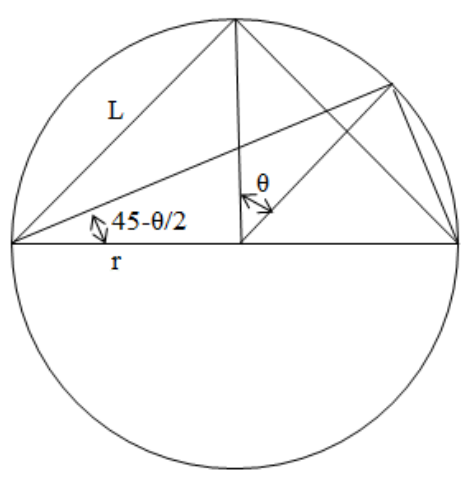

FIGURE III. WORKING PRINCIPLE DIAGRAM OF THE STEEL BELT

When the steel belt is under pulling force, there will be a small corner, the tumbler will create a corresponding corner and become heightened. As shown in figure 4, the distance between the fix point of steel belt and the center is $r$, and the effective length is

$$
L=r / \cos 45^{\circ}
$$

According to the measured torque, tension of steel belt is

$$
F=T /\left(2 \cdot r \cdot \cos 45^{\circ}\right)
$$

Where $F$ is the tensile force of steel belt, $T$ is the torque of transmission shaft.

Corner of the rotary body is got according to the tumbler's corner $\alpha$.

$$
\theta=\alpha \cdot R / r^{\prime}
$$

Where $r^{\prime}$ is the distance between the tumbler and shaft center.

$$
\Delta L=\frac{F L}{E A}=2 \cdot r \cdot \cos \left(45^{\circ}-\frac{\theta}{2}\right)-2 \cdot r \cdot \cos 45^{\circ}
$$

Where $\Delta L$ is the deformation of steel belt, $L$ is the original length, $A$ is the cross-sectional area of steel belt, $E$ is the elasticity modulus of steel belt material, and $\theta$ is the corner of the rotary body.

\section{RESEARCH On MEASUREMENT PRINCIPLE AND PRECISION OF TORQUE SENSOR}

\section{A. Torque Measurement Principle}

As shown in Figure $4(a), R_{1} \sim R_{4}$ are the strain gauges installed on the shell, where $R_{1}, R_{3}$ are fixed al ong the direction of the shaft, $R_{2}, R_{4}$ are fixed in vertical direction. 4 strain gauges are connected in full-bridge form as shown in figure 4(b). The deformation signal of shell is transmitted to resistance variation, then transmitted to voltage signal by the bridge.

$$
\Delta U=U K \cdot\left(\varepsilon_{1}-\varepsilon_{2}+\varepsilon_{3}-\varepsilon_{4}\right) / 4
$$

Where $U$ is the bridge voltage, $\Delta U$ is the output voltage of bridge, $K$ is the sensitivity coefficient of strain gauge, $\varepsilon$ is the strain value.

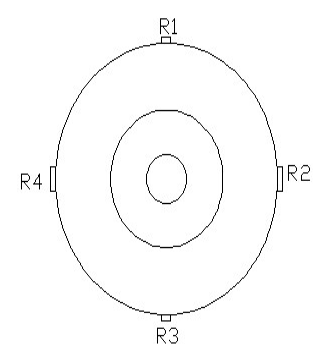

(a)Strain gauge installation diagram

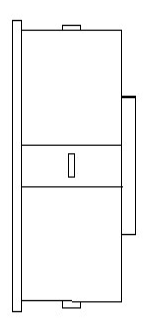

n
FIGURE IV. DIAGRAM OF STRAIN GAUGE INSTALLATION AND BRIDGE

We also know $\varepsilon_{1}=\varepsilon_{3}=\varepsilon$ and $\varepsilon_{2}=\varepsilon_{4}=\mu \varepsilon, \mu$ is the Poisson's ratio of the material.

So we get the equation below

$$
\Delta U=U K \cdot(\mu+1) \cdot \varepsilon / 2
$$

$$
\Delta U / U=K \cdot(1+\mu) \cdot \varepsilon / 2
$$

To ensure the sensor has enough output voltage, when $\Delta U / U(\mathrm{mV} / \mathrm{V})$ is 2 , we can calculate the maximum strain of shell is $\varepsilon$. Then we can calculate the height increase of tumbler $\Delta H$ and length of the shell deforming part $L_{0}$ from equation $\varepsilon=\Delta H / 2 L_{0}$.

\section{B. Experimental Research on Measurement Precision of the Sensor}

The signal acquisition system is shown in figure 5, which includes signal conditioner, data acquisition card and 
computer. The output signal of bridge is connected to the data acquisition system, which is firstly amplified and filtered by signal conditioner, then the conditioned signal is sampled, quantified and coded by data acquisition card, in order to transmit the analog signal to digital signal, and transferred to the computer.

The strain value of the shell can be calculated from (8)

$$
\Delta U=\mathrm{UK}(1+\mu) \cdot \varepsilon / 2=K_{1} \cdot \varepsilon
$$

Where $K_{1}$ is named accuracy coefficient, $K_{1}=U K(1+\mu) / 2$, which means the bridge output voltage of unit strain on the shell, and the theoretical value of accuracy coefficient is $6.757 \times 10^{-3} \mathrm{mv} / \mu \varepsilon$.

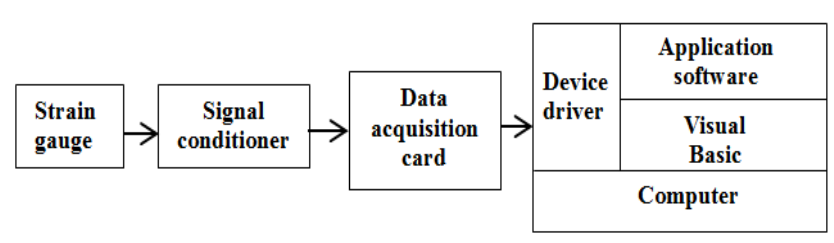

(Signal generation) (Signal conditioning) (A/D converter) (Acquisition, display, storage, analysis, etc.)

\section{FIGURE V. DIAGRAM OF SIGNAL ACQUISITION SYSTEM}

The strain gauges are installed on the shell and connected to the acquisition system, then the shell is fixed on the test-bed and a tensile force is applied to the shell to create a certain deformation, the torque sensor accuracy coefficient is calibrated according to the test results of the acquisition system.

TABLE I. CALIBRATION DATA OF SENSOR ACCURACY COEFFIENT

\begin{tabular}{|c|c|c|c|c|}
\hline $\begin{array}{c}\text { Shell } \\
\text { deformation } \\
(\mathbf{m m})\end{array}$ & $\begin{array}{c}\text { Output } \\
\text { voltage } \\
(\mathbf{m v})\end{array}$ & $\begin{array}{c}\text { Accuracy } \\
\mathbf{c o e f f i c i e n t} \\
\left(\mathbf{1 0}^{-3}\right. \\
\mathbf{m v} / \boldsymbol{\mu \varepsilon})\end{array}$ & $\begin{array}{c}\text { Error } \\
(\mathbf{\%})\end{array}$ & $\begin{array}{c}\text { Average } \\
\text { error } \\
(\mathbf{\%})\end{array}$ \\
\hline 0.071 & 9.41 & 6.627 & 2.0 & \multirow{2}{*}{2.5} \\
\hline 0.070 & 9.23 & 6.593 & 2.7 & \\
\hline 0.073 & 9.58 & 6.562 & 2.7 & \\
\cline { 1 - 3 } & & &
\end{tabular}

The theoretical result and experimental result of accuracy coefficient have a discrepancy of $2.5 \%$, influenced by the strain gauge installation skill, the tested sensitivity coefficient of strain gauge is lower than the nominal value, which results that the tested accuracy coefficient is lower than the theoretical value.

TABLE II. EXPERIMENTAL DATA OF MOTOR TEST-BED RESULTS AND TORQUE SENSOR MEASUREEMNT RESULTS

\begin{tabular}{|c|c|c|c|}
\hline $\begin{array}{c}\text { Test-bed data } \\
(\mathbf{K N} \cdot \mathbf{m})\end{array}$ & $\begin{array}{c}\text { Sensor data } \\
(\mathbf{K N} \cdot \mathbf{m})\end{array}$ & $\begin{array}{c}\text { Relative error } \\
(\mathbf{\%})\end{array}$ & $\begin{array}{c}\text { Average data } \\
(\mathbf{\%})\end{array}$ \\
\hline 15.4 & 14.9 & 3.2 & \multirow{2}{*}{3.3} \\
\cline { 1 - 3 } & 54.3 & 3.0 & \multirow{2}{*}{3.0} \\
\hline 82.5 & 79.4 & 3.7 & \\
\hline
\end{tabular}

The input shaft is connected to the motor, output shaft is connected to the motor test-bed, the output torque is tested by the test-bed and compared with the results of torque sensor as shown in table 2.The torque signal of third group of data in table 2 is shown in figure 6 , the torque amplitude steadily keeps the number of $79.4 \mathrm{KN} \cdot \mathrm{m}$.

Meanwhile, the torque of motor output shaft is calculated by extracting the power and rotate speed data of tested motor.

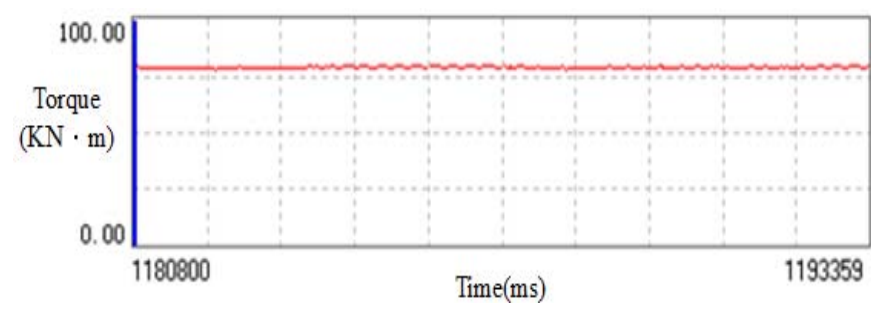

FIGURE VI. TORQUE SIGNAL OF MOTOR OUTPUT SHAFT

TABLE III. TORQUE CALCULATION DATA

\begin{tabular}{|c|c|}
\hline Item & Data \\
\hline Input power $(\mathrm{KW})$ & 4500 \\
\hline Efficiency $(\%)$ & 89 \\
\hline Speed $(\mathrm{rpm})$ & 500 \\
\hline Calculation torque $(\mathrm{KN} \cdot \mathrm{m})$ & 76.5 \\
\hline Test torque $(\mathrm{KN} \cdot \mathrm{m})$ & 79.4 \\
\hline Relative error $(\%)$ & 3.8 \\
\hline
\end{tabular}

The motor torque is calculated by input power, efficiency and rotate speed, which has a difference of $3.8 \%$ to the sensor test result of $79.4 \mathrm{KN} \cdot \mathrm{m}$. The motor test-bed result of torque is $82.5 \mathrm{KN} \cdot \mathrm{m}$, which has a difference of $3.7 \%$ to the sensor test result. Considering the working temperature, altitude and other factors which will have influence to working efficiency, it is basically proved that the principle of strain type brushless torque sensor is feasible and the test result is credible.

\section{TORque TEST EXPERIMENT OF RATATION SHAFT}

The five-stand six roller CVC rolling mill in some cold rolling plant is the biggest continuous cold rolling mill which has a occasionally obvious vibration in the running processes, especially the No.4 rolling mill has a more obvious vibration which leads marks on the surface of band steel.

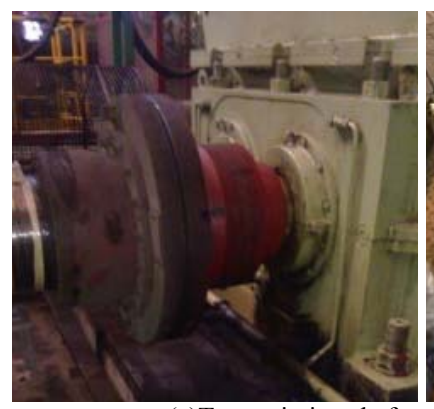

(a)Transmission shaft FIGURE VII. PICTURE OF FIELD TEST

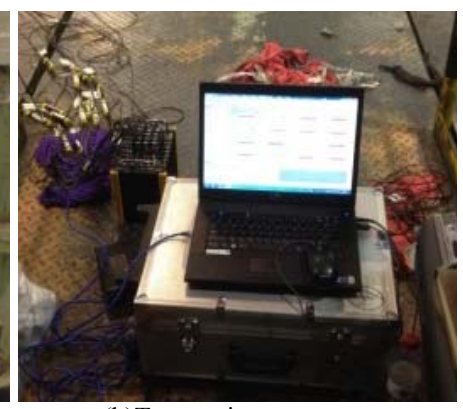

(b)Test equipmen
The brushless torque sensor is installed between the motor and transmission shaft for long time monitoring of the shaft torque. The transmission shaft is shown in figure 7(a), the online monitoring system is shown in figure 7(b).

During long time online monitoring, there is a obviously abnormal shaft torque signal during rolling SPHC band steel, 
the torque signal is shown in figure 8.The torque average value is set as zero point, the torque signal has a strong fluctuation around the zero point during a short time, the maximum value is $12 \mathrm{KN} \cdot \mathrm{m}$.

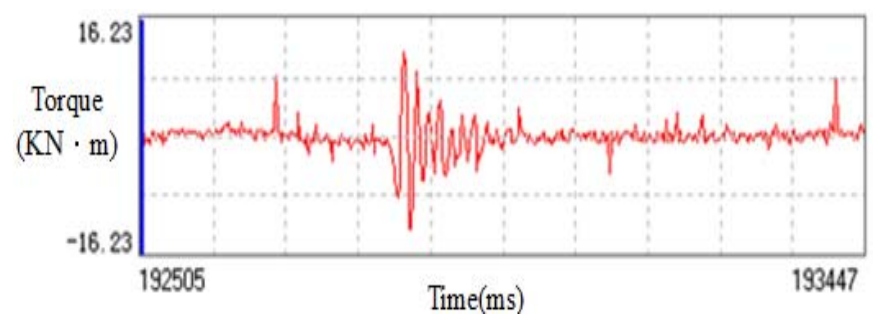

FIGURE VIII. TIME DOMAIN GRAPH OF MOTOR OUTPUT SHAFT TORQUE VIBRATION SIGNAL

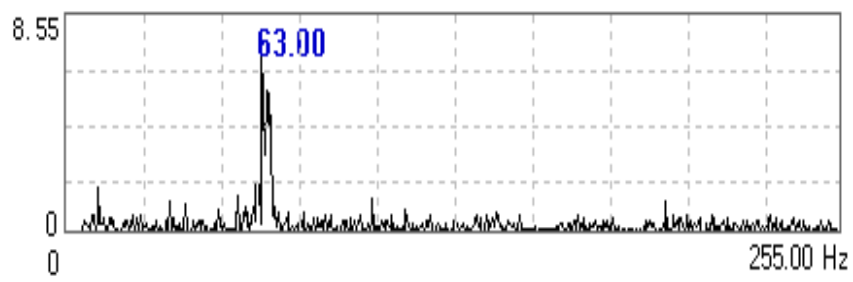

FIGURE IX. FREQUENCY RESPONSE OF ROLLONG MILL MOTOR OUTPUT SHAFT TORQUE VIBRATION SIGNAL

As shown in figure 9, it is found that the torque vibration main frequency of rolling motor output shaft is around $63.5 \mathrm{~Hz}$.

\section{Torsional Vibration InHEREnt Frequency Of The MAIN TRANSMISSION SHAFT}

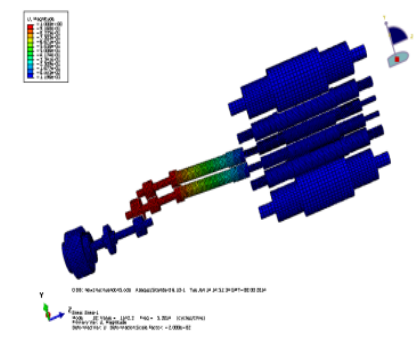

(a)First order

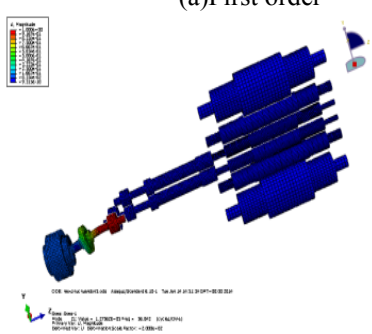

(c)Third order

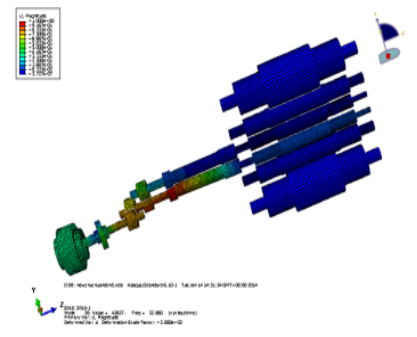

(b)Second order

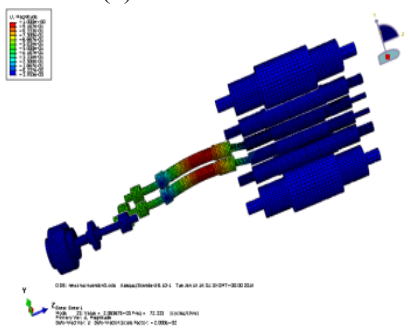

(d)Forth order
FIGURE X. TORSIONAL VIBRATION INHERENT FREQUENCY AND MODE OF ROLLING MILL MAIN TRANSMISSION SYSTEM

The rolling mill transmission system is analyzed by finite element simulation software, the inherent frequency and mode of vibration is obtained. Because the moment of inertia and stiffness is the main influence factor to the system vibration performance, tiny structures are ignored, the gears are simplified as cylinders by dimension and other components and parts are simplified on the basis of rotational inertia and stiffness.

The vibration mode of main transmission system is obtained by finite element mode analysis method, the inherent frequency and mode of first 4 orders of vibration are shown in figure 10 .

The first four orders vibration inherent frequency of rolling mill transmission system is $13 \mathrm{~Hz}, 33 \mathrm{~Hz}, 63 \mathrm{~Hz}, 72 \mathrm{~Hz}$. Where the third order mode is torsional vibration from motor to the reduction gearbox, and the vibration of the gear in the reduction gearbox is the most violent. There is an error of $0.8 \%$ between the third order inherent frequency $63 \mathrm{~Hz}$ and the torque measurement $63.5 \mathrm{~Hz}$, the two frequency values are basically matched which proved the reliability of torque measurement.

\section{CONCLUSION}

In this article, a brushless torque sensor is designed, which transfers the torque of transmission shaft to tensile deformation of the shell, and the torque of the shaft is obtained by measuring the strain of the shell. The torque amplitude measurement accuracy is verified by motor test-bed and motor power, speed data. A motor transmission shaft torque of some cold rolling production line is online monitored, the main frequency of transmission shaft torsional vibration is verified by the inherent characteristic finite element simulation result of rolling mill transmission system. From this work, the feasibility of the device and the correctness of the measurement are proved, which provides a basis to other torque measurement.

\section{ACKNOWLEDGMENT}

Research in this paper was supported by Beijing Higher Education Young Elite Teacher Project (YETP0368)

\section{REFERENCES}

[1] H. Defu, "Design of the strain torque sensor," Ship Engineering, vol. 194, pp. 96-99, April 2011.

[2] C. Jixin, W Enfeng, F Xiaoyan, "Several common resistance strain gauge rotary torque sensor," Metrology \& Measurement Technology, vol. 30, pp. 34-36, February 2010.

[3] Y. Zhiwen, F. Zhibin, H. Weina, "Torque measuring device's structural design and experimental analysis for drive shaft," China Measurement \& Test, vol. 41, pp. 120-123, January 2015.

[4] H. jinquan, W. Xiaopeng, Y. Hui, "Design of high-precision torque measurement system based on STM32," Transducer and Microsystem Technologies, vol. 34, pp. 99-101, April 2015.

[5] Y. Baolin, Y. Ying, L. Zeming, G. Shiqing, "Study on design principle of strain torque sensor," Machinery Design \& Manufacture, vol. 248, pp. 13-15, October 2011

[6] Z. Chunmei, W. Zhaoxia, H. Xiaofeng, "Design and study of torque measurement system," Machinery Design \& Manufacture, vol. 219, pp. 30-32, May 2009.

[7] Z. Haitao, T. Dunbing, X. Qin, "Measurement system of vehicle drive shaft dynamic torque based on SAW," Transactions of the Chinese Society for Agricultural Machinery, vol. 45, pp. 29-33, October 2014. 
[8] H. Zhen, L. Bin, D. Quanlin, “A study on torque measurement based on laser Doppler technology,” Acta Metrologica Sinica, vol. 28, pp. 61-63, January 2007.

[9] L. Kai, Y. Feng, H. Yinghui, "Torque measurement error analysis and compensation of electrical steering engine decelerator," Chinese Journal of Scientific Instrument, vol. 34, pp. 2271-2278, October 2013.

[10] L. Bin, Y. Haima, L. Jin, "Study on the dynamic torque measurement and feedback control of the jointed shaft of rolling mill," Chinese Journal of Scientific Instrument, vol. 26, pp. 537-541, May 2005.

[11] S. Guanlin, "New development of strain gauge measurement and transducer technique and applications in all kinds of engineers and domains," China Measurement \& Test, vol. 37, pp. 87-96, February 2011.

[12] M. Zong, L. Bin, "Research on the dynamic torque non-contact measurement of rotary machine," Acta Metrologica Sinica, vol. 27, pp. 364-367, April 2006 